\title{
Determinan Perilaku Penggunaan Kontrasepsi Pasca Persalinan di Wilayah Kerja Puskesmas Merdeka Kota Bogor
}

\author{
Agustina $^{1}$, Nawati ${ }^{2}$ \\ ${ }^{1,2}$ Program Studi Keperawatan Bogor, Politeknik Kesehatan Kemenkes Bandung \\ Email: nawati_sumaryadi@yahoo.co.id
}

\begin{abstract}
Determinant Behavioral Contraceptive Use After Labor in The Health Center Bogor City. Contraceptive use by women of reproductive age nationwide showed decreased from $61.4 \%$ (2007) to $55.86 \%$ (in 2010). In West Java amounted 59.8\%. Unmet need in Indonesia is $14 \%$ and in West Java is $11.1 \%$. Achievement of the family planning program active participant in Bogor reached $78.61 \%$ and the achievement of a new family planning program postpartum still low at $49.53 \%$ (BPMPM, Bogor 2013). The Purpose of research is to find out the determinant behavioral of contraceptive use post-natal in health center Bogor 2014.This research is quantitative with the design "Cross Sectional" study sample group of mothers aged 15-49 are married, have babies ages 6 weeks to 12 months is 111 respondents. The sampling technique is purposive sampling. The results of the bivariate analysis showed there is relation antenatal/ Ante Natal Care contraceptive use with $\mathrm{p}=0.031$ and the value of $\mathrm{OR}=0.2(95 \% \mathrm{CI}=0.44$ to 0.9$)$. This means that mothers during their pregnancy $\geq 4$ times have a great opportunity for not using contraception post partum was 0.2 times. Suggested to the health nurse at the health center in order to improve quality of care through counseling activities on family planning and counseling about contraception postpartum starting from pregnancy and continues into the postpartum period.
\end{abstract}

Keywords: Behavior, Contraception, Postpartum

\begin{abstract}
Abstrak: Determinan Perilaku Penggunaan Kontrasepsi Pasca Persalinan di Wilayah Kerja Puskesmas Merdeka Kota Bogor. Penggunaan kontrasepsi pada wanita usia subur secara nasional menunjukkan penurunan yaitu dari 61,4\% (tahun 2007) menjadi 55,86\% (tahun 2010). Di Provinsi Jawa Barat sebesar 59,8\%. Demikian pula unmet need di Indonesia sebanyak $14 \%$ dan di Jawa Barat sebanyak 11,1\%. Pencapaian peserta KB aktif di Kota Bogor mencapai 78,61\% dan pencapaian KB baru pascapersalinan masih rendah yaitu 49,53\% (BPMPM, Kota Bogor 2013). Tujuan penelitian untuk mengetahui determinan perilaku penggunaan kontrasepsi pasca persalinan di wilayah kerja puskesmas Merdeka Kota Bogor Tahun 2014. Penelitian ini bersifat kuantitatif dengan desain "Cross Sectional", sampel penelitian kelompok ibu yang berusia 15-49 sudah menikah, mempunyai bayi usia 6 minggu sampi 12 bulan sebanyak 111 responden. Teknik pengambilan sampel adalah purposive sampling. Hasil analisis bivariat menunjukkan ada hubungan pemeriksaan kehamilan/Ante Natal Care dengan penggunaan kontrasepsi dengan nilai $p=0,031$ dan nilai $\mathrm{OR}=0,2(\mathrm{CI} 95 \%=0,44-0,9)$. Artinya ibu yang memeriksakan kehamilan $\geq 4$ kali berpeluang besar untuk tidak menggunakan kontrasepsi pasca pesalinan sebesar 0,2 kali. Disarankan kepada perawat/ bidan kesehatan di Puskesmas agar meningkatkan kualitas pelayanan melalui kegiatan penyuluhan tentang Keluarga Berencana dan konseling tentang kontrasepsi pasca persalinan dimulai dari masa kehamilan dan berlanjut ke masa nifas.
\end{abstract}

Kata kunci: Perilaku, Kontrasepsi, Pasca persalinan

Angka Kematian Ibu (AKI) dan Angka Kematian Bayi (AKB) menjadi indikator keberhasilan pembangunan di bidang kesehatan. Penyebab langsung kematian ibu di Indonesia $80 \%$ karena komplikasi yang langsung seperti perdarahan $28 \%$, eklamsia $13 \%$, abortus yang tidak aman $11 \%$ dan infeksi $10 \%$. Sedangkan penyebab kematian ibu tidak langsung dipengaruhi oleh 4 kondisi kehamilan yang tidak ideal yang disebut "4 Terlalu" yaitu terlalu muda melahirkan, terlalu dekat jarak kelahiran, terlalu banyak anak dan terlalu tua untuk melahirkan.
Keluarga berencana mempunyai kontribusi yang besar terhadap upaya penurunan angka kematian ibu melahirkan. Pengetahuan ibu tentang pengendalian $\mathrm{KB}$ merupakan salah satu aspek penting dalam pemahaman tentang berbagai macam alat kontrasepsi, selanjutnya hal ini akan sangat berpengaruh terhadap pemakaian alat kontrasepsi yang tepat dan efektif. Pengetahuan ibu tentang cara dan alat KB modern sejak tahun 1991 sampai dengan tahun 2007 terus meningkat. Namun tidak berbanding lurus dengan jumlah angka penggunaannya. 
Penggunaan alat kontrasepsi pada wanita usia 1549 tahun yaitu dari $61,4 \%$ (tahun 2007) menjadi $55,86 \%$ (tahun 2010). Pada ibu pasca salin hal ini sangat perlu mendapatkan perhatian dari perawat maternitas sehingga ibu dapat segera mendapat informasi yang benar dan memutuskan untuk memanfaatkan pelayanan KB di fasilitas kesehatan.

Pelayanan KB pasca persalinan merupakan bagian dari pelayanan nifas berupa pemakaian alat/obat kontrasepsi oleh ibu atau suami segera setelah melahirkan sampai 42 hari setelahnya. Sebelumnya pada masa kehamilan, semestinya ibu juga mendapatkan penyuluhan dan konseling tentang KB pasca persalinan. Dalam pelayanan KB pasca persalinan ibu beserta suami mendapatkan nasihat tentang kapan kembalinya masa subur, waktu yang tepat untuk memulai aktifitas seksual dan kontrasepsi yang tepat dalam periode laktasi. Tujuan dari kontrasepsi pasca persalinan adalah untuk menurunkan unmet need, yaitu kelompok perempuan yang sebenarnya membutuhkan tetapi tidak terpenuhi.

Banyak faktor yang dapat mempengaruhi ibu dalam memanfaatkan pelayanan KB. pemanfaatan pelayanan kesehatan termasuk pelayanan $\mathrm{KB}$ dipengaruhi oleh tiga faktor yaitu faktor predisposing/ mempermudah, enabling/ pemungkin dan reinforcing/ penguat, salah satunya adalah upaya pendidikan kesehatan. Dalam perawatan post partum seorang perawat maternitas diharapkan dapat memanfaatkan pengetahuannya tentang kontrasepsi pascasalin, sehingga dapat memberikan pengetahuan kepada ibu dan suami sehingga mereka dapat mengambil keputusan berdasarkan pengetahuan yang baik tentang penatalaksaan kesuburan sebelum memulai hubungan seksual. Kunjungan nifas yang efektif berpengaruh teradap peningkatan pengetahuan ibu tentang $\mathrm{KB}$ dan juga pemanfaatannya.

Di Kota Bogor, pencapaian peserta KB baru pascasalin masih dirasakan sangat rendah. Hal ini disebabkan karena kesadaran masyarakat yang masih kurang dan pemilihan kontrasepsi yang masih kurang tepat (kontrasepsi jangka pendek misalnya suntik). Dari 6 Puskesmas Kecamatan di wilayah Kota Bogor, Puskesmas Kecamatan Bogor Barat merupakan wilayah yang jumlah peserta KB pascasalinnya masih rendah selain itu juga kunjungan nifas di puskesmas tersebut juga masih rendah yaitu $39 \%$.

Berdasarkan permasalahan yang telah dipaparkan maka perlu dilakukan penelitian mengenai "Determinan Perilaku Penggunaan Kontrasepsi Pasca Persalinan di Wilayah Kerja Puskesmas Merdeka Kota Bogor Tahun 2014”.

\section{METODE}

Rancangan penelitian ini adalah kuantitatif dengan desain Cross Sectional, lokasi penelitian dilaksanakan di wilayah kerja Puskesmas Merdeka Kota Bogor yang dilaksanakan pada bulan September 2014 s.d Desember 2014.

Populasi penelitian adalah wanita usia 1549 tahun sudah menikah dan mempunyai bayi atau anak terakhir usia 6 minggu sampai 12 bulan baik yang sudah menggunakan alat kontrasepsi maupun yang belum menggunakan kontrasepsi modern.

Sampel penelitian dipilih dengan menggunakan kriteria inklusi yaitu pernah kontak dengan petugas kesehatan selama periode kehamilan dan nifas serta bersedia diwawancarai. Alasan pembatasan usia anak terakhir 6 minggu s.d 12 bulan, mengingat jarak antara kelahiran yang sehat adalah lebih dari 2 tahun. Kriteria eksklusi, bila ibu yang mempunyai bayi atau anak terakhir usia 6 minggu s.d 12 bulan, tidak pernah kontak dengan petugas kesehatan selama periode kehamilan dan nifas. Besar sampel dalam penelitian ini sebesar 111 responden, pengambilan sampel menggunakan non random sampling dengan teknik purposive sampling.

\section{HASIL}

\section{A. ANALISIS UNIVARIAT}

Tabel 1. Distribusi Responden berdasarkan Umur, Pendidikan, Paritas, Umur Bayi

\begin{tabular}{|c|c|c|c|c|c|}
\hline Variabel & Jlh & $\%$ & $\begin{array}{c}\text { Mean } \\
\text { Median }\end{array}$ & SD & $\begin{array}{l}\text { Min- } \\
\text { Maks }\end{array}$ \\
\hline \multicolumn{6}{|l|}{ Umur } \\
\hline$\leq 30$ th & 60 & 54,1 & 28,35 & \multirow{2}{*}{6,24} & \multirow{2}{*}{$16-43$} \\
\hline$>30$ th & 51 & 45,1 & 28.00 & & \\
\hline \multicolumn{6}{|c|}{ Pendidikan } \\
\hline SD & 20 & 18 & Tinggi & \multirow{2}{*}{45} & \multirow{2}{*}{40,5} \\
\hline SMP & 46 & 41,4 & (SMU,PT) & & \\
\hline SMU & 41 & 36,9 & \multirow{2}{*}{$\begin{array}{c}\text { Rendah } \\
\text { (SD,SMP) }\end{array}$} & \multirow{2}{*}{66} & \multirow{2}{*}{59,5} \\
\hline PT & 4 & 3,6 & & & \\
\hline \multicolumn{6}{|l|}{ Paritas } \\
\hline$\leq 2$ anak & 84 & 75,7 & 2,04 & \multirow{2}{*}{1,198} & \multirow{2}{*}{$1-7$} \\
\hline$>2$ anak & 27 & 24,3 & 2,00 & & \\
\hline \multicolumn{6}{|l|}{ Umur bayi } \\
\hline$\leq 6,32 \mathrm{bln}$ & 62 & 55,9 & 6,32 & \multirow{2}{*}{3,76} & \multirow{2}{*}{$\begin{array}{l}1 \text { bln- } \\
12 \text { bln }\end{array}$} \\
\hline$>6,32$ bln & 49 & 44,1 & 6.00 & & \\
\hline
\end{tabular}

Berdasarkan tabel 1 diketahui umur responden hampir seimbang antara umur $<30$ tahun dan >30 tahun. Tingkat pendidikan responden paling banyak berpendidikan SMP 
$(41,4 \%)$, kategori tingkat pendidikan rendah sebanyak (59,5\%), paritas/jumlah anak sebagian besar memiliki anak $\leq 2$ sebanyak $(75,7 \%)$, umur bayi yang dimiliki responden sebagian besar berumur kurang dari 6 bulan.

Tabel 2. Distribusi Responden berdasarkan Akseptor KB

\begin{tabular}{lcclrr}
\hline Akseptor & Jlh & \% & Jenis KB & Jlh & \multicolumn{1}{c}{$\%$} \\
\hline Akseptor & 74 & 66,7 & Pil & 8 & 7,2 \\
\hline \multirow{2}{*}{$\begin{array}{l}\text { Tidak } \\
\text { Aksepetor }\end{array}$} & \multirow{2}{*}{37} & \multirow{2}{*}{33,3} & Suntik & 62 & 55,9 \\
\cline { 3 - 6 } & & & Implant & 2 & 1,8 \\
\cline { 3 - 6 } & & & & & \\
\end{tabular}

Distribusi akseptor KB responden sebagian besar sudah mengikuti KB yaitu 74 orang $(66,7 \%)$ sedangkan yang belum mengikuti KB adalah 37 orang $(33,3 \%)$. Dilihat dari jenis $\mathrm{KB}$ yang digunakan responden sebagian besar adalah menggunakan KB suntik yaitu 62 orang $(55,9)$.

Tabel 3. Distribusi Responden berdasarkan Tempat Mendapatkan Pelayanan KB

\begin{tabular}{lcc}
\hline Tempat Pelayanan & Jlh & \% \\
\hline Puskesmas & 35 & 31,5 \\
\hline RS & 2 & 1,8 \\
\hline Praktik bidan/dr & 29 & 26,1 \\
\hline PLKB & 4 & 3,6 \\
\hline Posyandu & 4 & 3,6 \\
\hline
\end{tabular}

Dilihat dari tempat mendapatkan pelayanan KB responden sebagian besar di Puskesmas yaitu 35 orang $(31,5 \%)$ dan di Praktik Bidan/ dokter yaitu 29 orang $(26,1 \%)$, sebagian kecil di posyandu dan PLKB yaitu masing-masing 4 orang $(3,6 \%)$.

\section{B. ANALISIS BIVARIAT}

Tabel 4. Hubungan Umur, Tk Pendidikan, Paritas, Umur Bayi, Tk Pengetahuan, Niat Reproduksi, Otonomi, Anc, Kunjungan Nifas, Konseling dengan Perilaku Penggunaan Kontrasepsi Pasca Persalinan

\begin{tabular}{|c|c|c|c|c|c|c|c|c|}
\hline \multirow{3}{*}{ Variabel } & \multicolumn{4}{|c|}{ Akseptor } & \multirow{2}{*}{\multicolumn{2}{|c|}{ Total }} & \multirow{3}{*}{$\begin{array}{c}\text { OR } \\
(95 \% \mathrm{CI})\end{array}$} & \multirow{3}{*}{$p$-value } \\
\hline & \multicolumn{2}{|c|}{ Menggunakan } & \multicolumn{2}{|c|}{ Tdk menggunakan } & & & & \\
\hline & $\mathbf{n}$ & $\%$ & $\mathbf{n}$ & $\%$ & $\mathbf{n}$ & $\%$ & & \\
\hline \multicolumn{9}{|l|}{ Umur } \\
\hline$\leq 30$ th & 42 & 70 & 18 & 30 & 60 & 100 & 1,385 & \multirow{2}{*}{0,54} \\
\hline$>30$ th & 32 & 62,7 & 19 & 37,3 & 51 & 100 & $0,6-3,05$ & \\
\hline \multicolumn{9}{|l|}{ Tk. Pendidikan } \\
\hline Tinggi (SMU,PT) & 26 & 57,8 & 19 & 42,2 & 45 & 100 & 0,51 & \multirow{2}{*}{0,151} \\
\hline Rendah (SD,SMP) & 48 & 72,7 & 18 & 27,3 & 66 & 100 & $0,2-1,1$ & \\
\hline \multicolumn{9}{|l|}{ Paritas } \\
\hline$\leq 2$ anak & 58 & 69 & 26 & 31 & 84 & 100 & 1,534 & \multirow{2}{*}{0,481} \\
\hline$>2$ anak & 16 & 59,3 & 11 & 40,7 & 27 & 100 & $0,6-3,7$ & \\
\hline \multicolumn{9}{|l|}{ Umur Bayi } \\
\hline Muda $(\leq 6,32 \mathrm{bl})$ & 38 & 61,3 & 24 & 38,7 & 62 & 100 & 0,572 & \multirow{2}{*}{0,251} \\
\hline Tua $(>6,32 \mathrm{bl})$ & 36 & 73,5 & 13 & 26,5 & 49 & 100 & $0,2-1,2$ & \\
\hline \multicolumn{9}{|l|}{ Tk. Pengetahuan } \\
\hline Baik & 8 & 66,7 & 4 & 33,3 & 12 & 100 & 1 & \multirow{2}{*}{1} \\
\hline Kurang & 66 & 66,7 & 33 & 33,3 & 99 & 100 & $0,2-3,5$ & \\
\hline \multicolumn{9}{|l|}{ Niat Reproduksi } \\
\hline Membatasi & 35 & 74,4 & 12 & 25,5 & 47 & 100 & 1,870 & \multirow{2}{*}{0,197} \\
\hline Tidak membatasi & 39 & 60,9 & 25 & 39,1 & 64 & 100 & $0,8-4,2$ & \\
\hline \multicolumn{9}{|l|}{ Otonomi } \\
\hline Tinggi & 36 & 72 & 14 & 28 & 50 & 100 & 1,556 & \multirow{2}{*}{0,381} \\
\hline Rendah & 38 & 62,3 & 23 & 37,7 & 61 & 100 & $0,6-3,4$ & \\
\hline \multicolumn{9}{|l|}{ KunjunganANC } \\
\hline $\mathrm{ANC} \geq 4 \mathrm{kali}$ & 58 & 62,4 & 35 & 37,6 & 93 & 100 & 0,207 & \multirow{2}{*}{0,031} \\
\hline ANC $<4$ kali & 16 & 88,9 & 2 & 11,1 & 18 & 100 & $0,04-0,9$ & \\
\hline \multicolumn{9}{|l|}{ Kunjungan Nifas } \\
\hline Nifas $\geq 3 \mathrm{kali}$ & 24 & 70,6 & 10 & 29,4 & 34 & 100 & 1,296 & \multirow{2}{*}{0,716} \\
\hline Nifas $<3$ kali & 50 & 64,9 & 27 & 35,1 & 77 & 100 & $0,54-3,1$ & \\
\hline \multicolumn{9}{|l|}{ Konseling KB } \\
\hline Cukup & 40 & 71,4 & 16 & 28,6 & 56 & 100 & 1,544 & \multirow{2}{*}{0,383} \\
\hline Kurang & 34 & 61,8 & 21 & 38,2 & 55 & 100 & $0,6-3,4$ & \\
\hline
\end{tabular}


Berdasarkan tabel 4, dari 111 responden diperoleh bahwa sebanyak 18 (30\%) ibu yang berumur $\leq 30$ th tidak menggunakan kontrasepsi. Sedangkan ibu yang berumur $>30$ th sebanyak 19 $(37,3 \%)$ yang tidak menggunakan kontrasepsi. Ibu yang berpendidikan tinggi sebanyak 19 $(42,2 \%)$ tidak menggunakan kontrasepsi. Sedangkan ibu yang berpendidikan rendah sebanyak $18(27,3 \%)$ tidak menggunakan konrasepsi.

Ibu paritas $\leq 2$ anak tidak menggunakan kontrasepsi sebanyak 26 (31\%), sedangkan ibu dengan papritas $>2$ anak sebanyak $11(40,7 \%)$ tidak menggunakan konrasepsi. Ibu dengan umur bayi $\leq 6,32$ bulan sebanyak 24 (38\%) tidak menggunakan kontrasepsi. Sedangkan ibu dengan umur bayi $>6,32$ bulan sebanyak $13(26,5 \%)$ tidak menggunakan konrasepsi.

Ibu dengan pengetahuan baik sebanyak 4 $(33,3 \%)$ tidak menggunakan kontrasepsi, demikinan pula sebanyak $33 \quad(33,3 \%)$ ibu pengetahuan kurang tidak menggunakan konrasepsi. Ibu dengan niat reproduksi membatasi sebanyak $12 \quad(25,5 \%)$ tidak menggunakan kontrasepsi. Sedangkan ibu niat tidak membatasi sebanyak $25(39,1 \%)$ tidak menggunakan konrasepsi.

Ibu dengan otonomi tinggi tidak menggunakan kontrasepsi sebanyak $14(28, \%)$. Sedangkan ibu dengan otonomi rendah sebanyak $23 \quad(37,7 \%)$ tidak menggunakan konrasepsi. Ibu dengan ANC $\geq 4$ kali tidak menggunakan kontrasepsi sebanyak 35 (37,6\%), sedangkan ANC <4 kali sebanyak $2(11,1 \%)$ tidak menggunakan konrasepsi.

Ibu dengan kunjungan nifas $\geq 3$ kali tidak menggunakan kontrasepsi sebanyak $10(29,4 \%)$, sedangkan kunjungan nifas <3 kali sebanyak 27 $(35,1 \%)$ tidak menggunakan konrasepsi. Ibu dengan konseling cukup tidak menggunakan kontrasepsi sebanyak $16(28,6 \%)$, Sedangkan konseling kurang sebanyak $21(38,2 \%)$ tidak menggunakan konrasepsi.

Hasil analisis hubungan antara umur, tingkat pendidikan, paritas, umur bayi, tingkat pengetahuan, niat reproduksi, otonomi, kunjungan nifas dan konseling di peroleh ( $p$ value $>0,05)$, berarti dapat disimpulkan tidak ada hubungan yang signifikan antara umur dengan penggunaan kontrasepsi.

Hasil uji statistik didapatkan nilai ( $p$ value $=0,031)$ maka dapat disimpulkan ada hubungan yang siqnifikan antara kunjungan ANC dengan penggunaan kontrasepsi.

\section{PEMBAHASAN}

\section{A. ANALISIS UNIVARIAT}

Pada tabel 2 sebagian besar responden yang menjadi akseptor menggunakan jenis kontrasepsi suntik $(83,7 \%)$. Hal ini sesuai dengan hasil penelitian Widdefrita (2011) di Kota Padang Sumatra Barat di dapatkan 68,3\%. Alasan tingginya penggunaan $\mathrm{KB}$ suntik karena sudah sangat dikenal oleh masyarakat, yang didukung oleh pengetahuan responden tentang jenis kontrasepsi sebagian besar menjawab suntik. Kontrasepsi suntik dapat diterima masyarakat karena proses pemakaiannya tidak karena harus memperlihatkan organ intim seperti pemasangan IUD.

Tempat mendapatkan atau memasang kontrasepsi sebagian besar responden mendapatkan Puskesmas 35 (31,5\%) dan praktik bidan swasta (BPS) 29 (26,1\%). Ini tentu sangat baik karena masyarakat khususnya ibu sedah memanfaatkan pelayanan Puskesmas dengan baik, sehingga perlu lebih ditingkatkan lagi mutu pelayanan KIA di Puskesmas.

\section{B. ANALISIS BIVARIAT}

\section{Hubungan Umur dengan Penggunaan Kontrasepsi}

Hasil analisis bivariat dengan menggunakan uji statistik chi square diperoleh p-value 0,544 artinya tidak ada hubungan bermakna antara umur responden dengan penggunaan kontrasepsi. Hasil penelitian ini sejalan dengan penelitian Widdefrita (2011). Namun demikian ada kecenderungan ibu yang umurnya $>30$ tahun banyak yang tidak menggunakan alat kontrasepsi dibandingkan ibu yang umurnya $<30$ tahun. Hal ini sejalan dengan hasil analisis lanjut SDKI 2007 oleh Maika, dimana diperoleh korelasi negatif artinya semakin tua usia responden semakin menurun kecendrungan pemakaian kontrasepsi.

Tentunya hal ini perlu mendapatkan perhatian yang serius dari petugas kesehatan termasuk perawat maternitas, mengingat usia reproduksi wanita tidak dilihat dari berapa jumlah anak yang telah dilahirkan, melainkan dari usia reproduksinya yaitu antara 15 s.d 51 tahun. Artinya jika ibu dalam kurun usia tersebut tidak menjadi akseptor, sedangkan masih seksual aktif maka resiko untuk hamil masih sangat memungkinkan. 


\section{Hubungan Tingkat Pendidikan dengan Penggunaan Kontrasepsi}

Hasil analisis bivariat dengan menggunakan uji statistik chi square diperoleh p-value 0,151 artinya tidak ada hubungan bermakna antara tingkat pendidikan responden dengan penggunaan kontrasepsi. Penggunaan kontrasepsi banyak ditemui pada responden yang tingkat pendidikan rendah dibandingkan tingkat pendidikan tinggi. Hasil penelitian ini tidak sejalan dengan penelitian Hadiat (2007).

Tidak sesuainya hasil temuan ini dengan teori dan penelitian lain diperkirakan karena responden dengan tingkat pendidikan relatif tinggi memiliki pemahaman tentang efek samping. Faktor lain kemungkinan paparan terhadap informasi $\mathrm{KB}$, seseorang dengan tingkat pendidikan tinggi tetapi yang tidak terpapar dengan informasi tentang kontrasepsi dengan kuantitas dan kualitas yang cukup, pendidikan tersebut tidak akan memberi perilaku positif bagi individu tersebut.

\section{Hubungan Paritas dengan Penggunaan Kontrasepsi}

Hasil analisis bivariat dengan menggunakan uji statistik chi square diperoleh $p$ value 0,481 artinya tidak ada hubungan bermakna antara jumlah anak hidup dengan penggunaan kontrasepsi pasca persalinan. Responden yang tidak menggunakan kontrasepsi banyak terjadi pada ibu dengan paritas $>2$ dibandingkan dengan ibu paritas $<2$ anak.

Hasil penelitian ini sejalan dengan penelitian Widdefrita (2011), yang menyatakan pemakaian kontrasepsi pasca persalinan banyak ditemui pada responden dengan anak sedikit dibandingkan anak banyak. Prevalensi penggunaan kontrasepsi mungkin berhubungan dengan jumlah anak. Badan Koordinasi Keluarga Berencana Nasional, telah menetapkan "dua anak lebih baik" yang mengisyaratkan agar pasangan usia subur mempunyai anak ideal dalam upaya pengaturan dan menurunkan angka kelahiran.

Selain itu pula hasil penelitian ini diperkirakan terkait dengan pemahaman responden terhadap motto BKKBN "dua anak lebih baik" yang memberi nilai positif dalam membesarkan dan mendidik anak. Akibatnya meskipun responden memiliki anak 1-2 orang, tapi kontrasepsi merupakan kebutuhan bagi mereka agar anak dan rumah tangga mereka lebih baik. Oleh karena itu variabel jumlah anak menjadi tidak bermakna dengan penggunaan kontrasepsi pasca persalinan.

\section{Hubungan Umur Bayi dengan Penggunaan Kontrasepsi}

Hasil analisis bivariat dengan menggunakan uji statistik chi square diperoleh $p$ - value 0,251 artinya tidak ada hubungan bermakna antara umur bayi dengan penggunaan kontrasepsi. Ibu yang tidak menggunakan kontrasepsi lebih banyak pada ibu yang mempunyai bayi dengan umur tua (6 bulan), dibandingkan dengan ibu yang umur bayinya $<6$ bulan. Tingginya penggunaan kontrasepsi pasca persalinan pada bayi usai muda pada penelitian ini, kemungkinan karena masih rendahnya perilaku ASI eksklusif yang dapat dijadikan sebagai Metoda Amenore Laktasi dan kurangnya rasa aman bagi responden.

Umur bayi dapat mempengaruhi penggunaan kontrasepsi pasca persalinan. Pasangan dengan umur anak masih kecil dan tidak menginginkan anak cendrung menunda pemakaian kontrasepsi permanen sampai mereka cukup yakin bahwa anak mereka dapat bertahan hidup. Seorang wanita yang baru melahirkan mungkin lebih cendrung menggunakan Metode Amenore Laktasi (MAL) atau kontrasepsi jangka pendek yang dapat digunakan saat menyusui.Hasil penelitian ini sesuai dengan penelitian widdefrita (2011) yang menyatakan tidak ada hunbungan antara umur bayi dengan perilaku penggunaan kontrasepsi pasca persalinan.

\section{Hubungan Tingkat Pengetahuan tentang Kontrasepsi dengan Perilaku Penggunaan Kontrasepsi \\ Hasil uji chi square tidak ada hubungan} bermakna antara tingkat pengetahuan responden dengan penggunaan kontrasepsi pasca persalinan (p-value 1.000).

Dari hasil analisis menunjukan bahwa responden yang tingkat pengetahuannya baik dan yang kurang baik, kecenderungan sama untuk menggunakan dan tidak menggunakan akseptor $\mathrm{KB}$.

Hasil penelitian ini tidak sejalan dengan penelitian Widdefrita (2011) yang menyatakan ada hubungan bermakna antara tingkat pengetahuan responden dengan penggunaan kontrasepsi pasca persalinan.

Perbedaan ini kemungkinan sebaran tingkat pengetahuan responden yang tidak seimbang antara yang pengetahuan baik dan yang tidak, dimana pada responden yang pengetahuanya kurang sebanyak 99 orang dari 111 responden. Hal ini mempengaruhi hasil analisis tabel silang/ crosstabs dari uji chi square. 


\section{Hubungan Niat Reproduksi dengan Perilaku Penggunaan Kontrasepsi Pasca Persalinan}

Hasil uji statistik chi square diperoleh $p$ value 0,19 artinya tidak ada hubungan antara niat reproduksi dengan penggunaan kontrasepsi pasca persalinan. Pemakaian kontrasepsi pasca persalinan pada ibu dengan niat reproduksi tidak membatasi jumlah kehamilan lebih banyak yang tidak menggunakan kontrasepsi yaitu sebanyak $39,1 \%$. Hal ini menunjukkan bahwa kesadaran ibu untuk memperhatikan fungsi reproduksi mulai baik.

Menurut Ajzen dan Fishbein (2005), niat adalah indikator terbaik untuk mempredikasikan perilaku, khusunya ketika seseorang bertindak dibawah kontrol kemauan mereka. Niat dibentuk oleh tiga faktor yaitu sikap untuk berperilaku, norma subjektif, dan keyakinan kontrol perilaku. Ajzen dan Fishbein menyatakan bahwa niat mengendalikan aktifitas seseorang dari belakang dan elemen utama mengenai rencana perilaku mereka. Niat adalah pertimbangan yang mencerminkan keputusan mengenai rencana reproduksi seseorang yang mengarahkan mereka terhadap rencana nyata dengan hasil yang jelas seperti keinginan mempunyai anak dalam jangka waktu tertentu.

\section{Hubungan Otonomi dengan Perilaku Penggunaan Kontrasepsi Pasca Persalinan}

Hasil analisis bivariat dengan menggunakan uji statistik chi square diperoleh p-value 0,381 artinya tidak ada hubungan bermakna antara otonomi dengan penggunaan kontrasepsi pasca persalinan. Pemakaian kontrasepsi pasca persalinan banyak ditemui pada responden yang mempunyai otonomi tinggi $72 \%$ dibandingkan otonomi rendah $62,3 \%$.

Menurut Hadiat dkk (2007) terdapat hubungan antara posisi wanita dalam rumah tangga dan masyarakat dengan fenomena kematian ibu. Meskipun seorang wanita mempunyai tingkat pendidikan yang rendah bila memiliki otonomi dalam mengambil keputusan dalam proses reproduksi didukung oleh pengetahuan yang baik akan memberikan kontribusi yang baik terhadap penurunan AKI dan AKB.

Dalam pengambilan keputusan yang berhubungan dengan reproduksi, keputusan wanita lebih menentukan terlihat dari kemampuan responden memutuskan untuk menggunakan kontrasepsi atau tidak. Mereka yang mempunyai otonomi tinggi dalam proses reproduksi beralasan bahwa untuk kehamilan dan kelahiran merupakan takdir sebagai wanita, tapi wanita perlu diberi kesempatan untuk pemulihan kesehatan dari proses reproduksi dengan ber-KB.

\section{Hubungan Pemanfaatan Pelayanan ANC dengan Perilaku Penggunaan Kontrasepsi Pasca Persalinan}

Hasil uji chi square ada hubungan bermakna antara pemanfaatan pelayanan ANC dengan penggunaan kontrasepsi pasca persalinan ( $p$ value 0,031 ). Hasil analisis didapatkan $\mathrm{OR}=0,207$ (CI $95 \%=0,04-0,9$ ). artinya responden yang memanfaatkan pelayananan ANC baik $\geq$ berpeluang besar untuk tidak menggunakan kontrasepsi pasca pesalinan sebesar 0,2 kali.

Menurut Hotchkiss (2002), wanita yang menggunakan pelayanan KIA terpapar terhadap usaha konseling dan promosi mengenai KB. Harapan dengan meningkatnya frekuensi kunjungan ANC akan meningkatkan paparan terhadap informasi KB. Tiga model pemaparan responden terhadap informasi KB saat kunjungan pelayanan KIA yaitu konseling petugas kesehatan, diskusi dengan pasien dan paparan dengan media KIE.Selama periode kehamilan dan kunjungan kesehatan bayi hamper $80 \%$ wanita dilaporkan melihat materi KIE.

Penelitian yang sesuai juga didapatkan oleh Maika 2009 bahwa ada hubungan bermakna antara frekuensi kunjungan ANC dengan penggunaan kontrasepsi pasca persalinan dengan korelasi positif sebesar 0,067 , yang berarti semakin sering responden memeriksakan kehamilan semakin meningkat kecendrungan untuk menggunakan kontrasepsi pasca persalinan.

Dari teori dan hasil penelitian ini dapat disimpulkan bahwa frekuensi kunjungan ANC akan meningkatkan paparan responden terhadap informasi KB. Vernon (2009) menyatakan alasan ditawarkanya KB dalam pelayanan ANC: memberikan waktu untuk menetapkan dengan pasangan terhadap niat fertility yang akan datang sebelum memilih dan memulai suatu metode kontrasepsi. Memungkinkan wanita untuk membuat keputusan dan memulai suatu metode segera setelah persalinan.

Diperlukan upaya peningkatan kualitas pelayanan ANC dengan memberikan informasi tentang KB dari petugas kesehatan. Dapat disimpulkan konseling pada saat kunjungan ANC dapat dijadikan strategi untuk memperkenalkan kontrasepsi sehingga dapat meningkatkan penggunaan kontrasepsi pasca persalinan, hal ini juga merupakan upaya mendukung program $\mathrm{P} 4 \mathrm{~K}$ (Program Perencanaan Persalinan dan Pencegahan Komplikasi). 
9. Hubungan Pemanfaatan Pelayanan Nifas dengan Perilaku Penggunaan Kontrasepsi Pasca Persalinan.

Hasil uji chi square diperoleh hasil tidak hubungan bermakna antara pemanfaatan pelayanan nifas dengan penggunaan kontrasepsi pasca persalinan ( $p$-value 0,716$)$.

Namun demikian dari hasil penelitian ini menunjukkan ada kecenderungan ibu nifas yang melakukan kunjungan nifas baik ( $\geq 3$ kali) lebih banyak yang menjadi akseptor.

Salah satu pelayanan kesehatan yang diberikan pada masa nifas adalah melakukan penyuluhan dan konseling pada ibu, keluarga mengenai KB pasca persalinan. Nasehat petugas kesehatan mengenai jarak kelahiran atau terminasi terhadap fertility berikutnya akan memperkuat keinginan mereka tentang adaptasi KB pasca persalinan.

Pemanfaatan pelayanan nifas dapat meningkatkan penggunaan kontrasepsi pasca persalinan. Kunjungan nifas yang dilakukan oleh responden dapat dijadikan peluang emas untuk menyampaikan pesan KB pada wanita pasca persalinan sebelum memulai aktifitas seksual.

\section{Hubungan Konseling dengan Perilaku Penggunaan Kontrasepsi Pasca Persalinan}

Hasil uji chi square tidak ada hubungan antara konseling dengan penggunaan kontrasepsi pasca persalinan ( $p$-value 0,383). Hasil penelitian ini menunjukkan responden yang mendapatkan konseling KB yang cukup, kecenderungan akan menjadi akseptor lebih banyak dibandingkan dengan yang kurang.

Menurut Upadhyay (2002), wanita lebih sering memanfaatkan pelayanan Kesehatan Ibu dan Anak (KIA) pada periode prenatal, postpartum dan sampai satu tahun setelah kelahiran dimana hal tersebut adalah waktu yang sangat penting untuk mendapatkan informasi dan konseling tentang menjarangkan kehamilan.

Konseling merupakan aspek yang sangat penting dalam pelayanan $\mathrm{KB}$ dan kesehatan reproduksi. Dengan melakukan konseling berarti petugas membantu klien dalam memilih dan memutuskan jenis kontrasepsi yang akan digunakan sesuai dengan pilihan ibu dan pasangannya (Saifuddin, 2004).

Seperti yang telah ditetapkan dalam program $\mathrm{P} 4 \mathrm{~K}$ bahwa pada trimester terakhir kehamilan, wanita telah memutuskan rencana persalinan dan penggunaan kontrasepsi pasca persalinan. Bila informasi dan konseling tentang kontrasepsi pasca persalinan dilaksanakan maka tidak akan sulit untuk melaksanakan program $\mathrm{KB}$ pasca pesalinan.

\section{SIMPULAN}

1. Karakteristik responden: umur responden didominasi antara umur 30 tahun, tertinggi usia 43 tahun dan terendah 16 tahun, dengan latar belakang pendidikan SLTP. Sebagian besar responden memiliki jumlah anak/ atau paritas $\leq 2$ anak dan umur anak terakhir $\leq 6,3$ bulan.

2. Tingkat pengetahuan responden tentang $\mathrm{KB}$ sebagian besar kurang, niat reproduksi sebagian responden tidak membatasi, dengan otonomi atau kemampuan memutuskan sendiri keikutsertaan $\mathrm{KB}$ yang tinggi.

3. Pemanfaatan pelayanan ANC sebagian besar sudah baik yaitu lebih dari 4 kali kunjungan. Sedangkan kunjungan nifas sebagain besar responden kurang baik yakni kurang dari 3 kali, demikian pula dengan pelayanan konseling $\mathrm{KB}$ yang pernah diperoleh juga sebagian besar belum baik.

4. Terdapat hubungan yang signifikan antara kunjungan ANC dengan penggunaan kontrasepsi pasca persalinan ( $p$-value 0,031). Responden yang memanfaatkan pelayananan ANC baik berpeluang besar untuk tidak menggunakan kontrasepsi pasca pesalinan sebesar 0,2 kali.

5. Tidak ada hubungan yang siqnifikan antara umur, tingkat pendidikan, paritas, tingkat pengetahuan, niat reproduksi, otonomi, kunjungan nifas dan konseling $\mathrm{KB}$ dengan penggunaan kontrasepsi pasca persalinan.

\section{SARAN}

1. Bagi Puskesmas

Agarmeningkatkan kualitas pelayanan ANC dan nifas dengan memberikan penyuluhan tentang Keluarga Berencana dan konseling tentang kontrasepsi pasca persalinan.

2. Bagi keluarga pasien

Agar turut bersama-sama berpartipasi aktif dengan melibatkan suami dalam kegiatan kunjungan ANC, persalinan dan nifas.

3. Bagi Peneliti Selanjutnya

Perlu dilakukan penelitian lebih lanjut mengenai perilaku penggunaan kontrasepsi dengan menggunakan desain quasi eksperimen dengan memberikan pajanan informasi audio visual pada ibu hamil. 


\section{DAFTAR PUSTAKA}

Ajzen, Icek., Fishbein. 2005. Attitudes, Personality and Behavior. New York: Mc Graw Hill Open University Press.

Badan Pusat Statistik (BPS) dan Macro International. 2007. Survei Demografi dan Kesehatan Indonesia.

Hadiat, dkk. 2007. Rancang Bangun Percepatan Penurunan Angka Kematian Ibu: Untuk Mencapai Sasaran Mellinium Development Goals. Jakarta: Bappenas.

Hartanto, Hanafi. 2004. Keluarga Berencana dan Kontrasepsi. Jakarta: Pustaka Sinar Harapan.

Hotchikiss D, J Rous, E Seiber and Aberruti, 2002. The Influence od maternal and Child Health Service Utilazation and Acces to private Sector Family Planning Service on subsequent contraceptive Use: A Multicountry Study. USAID Commercial Market Strategi Project. Washington DC.
Maika, A \& Wahyono. 2009. Analisis Lanjut SDKI 2007: Penggunaan Alat Kontrasepsi Pasca Melahirkan. KB dan Kesehatan Reproduksi. Jakarta: BKKBN..

Upadhyay, Ushma D. 2001. Informed Choice in Family Planning: Helping People Decide. Population Report, Series J No 50 Population Information Program, Spring. John Hopkins University Bloomberg School of Public Health, Baltimore.

Vernon, Ricardo. 2009. Delivering Family Planning Information and Service to Postpartum Women in Clinic Settings. Population Council. Washington, DC.

Widdefrita. 2011. Determinan Perilaku Penggunaan Kontrasepsi Pasca Persalinan di Wilayah kerja Puskesmas Air Dingin Kecamatan Koto Tangah Kota Padang. Padang. 